\title{
Lago de São Simão e o desenvolvimento do turismo rural: uma nova atividade econômica sustentada pelo trabalho familiar
}

\section{São Simão Lake and the development of rural tourism: a new economic activity supported by family work}

\author{
Elinéia Lima Santana, Jean Carlos Vieira Santos ${ }^{1}$
}

\section{RESUMO}

O estudo aqui proposto investigou uma pousada rural às margens do rio dos Bois, afluente do rio Paranaíba, no estado de Goiás. Como uma empresa familiar com infraestrutura, equipamentos, serviços de animação e lazer, ela tem potencializado o desenvolvimento do turismo rural no município de Gouvelândia, Goiás. Diante disso, este artigo tem como objetivo apresentar e analisar o perfil dos visitantes que chegam à Pousada Rio dos Bois, ao veicular tal abordagem associada à prática do turismo rural numa paisagem de "sol e água" sustentada por uma base econômica familiar. Os resultados apresentados conjugam os levantamentos efetuados durante os trabalhos de campo, a aplicação de questionários, as entrevistas informais, o levantamento fotográfico e a pesquisa bibliográfica. $O$ universo da pesquisa foi composto por 50 turistas que se hospedaram no referido estabelecimento hoteleiro, entre maio e setembro de 2015. A investigação de campo envolveu períodos de finais de semana e feriados, visando à identificação de algumas características dos turistas e visitantes. Utilizaram-se métodos mistos, com destaque para o "analítico" e o "quantitativo", haja vista que existe uma relação próxima entre eles. Destacou-se que os maiores grupos de visitantes são das cidades de Rio Verde (25\%) e Quirinópolis (25\%), demonstrando que os turistas que chegam ao destino são oriundos de lugares localizados num raio de 150 quilômetros. $O$ tempo de permanência dos turistas no empreendimento rural é de, no máximo, três dias; logo, a paisagem pesquisada ainda carece de mais investimentos.

PALAVRAS-CHAVE: Gouvelândia; Turismo Rural; Economia Familiar; Conteúdos Rurais. 


\section{ABSTRACT}

The proposed study investigates a rural inn on the banks of dos Bois river, an affluent of Paranaiba River in the state of Goiás. As a family organization with infrastructure, equipment, entertainment and leisure services, it is boosting the development of rural tourism in Gouvelândia, Goiás. Thus, this article aims to present and analyze the profile of visitors that arrive in Pousada Rio dos Bois, reporting this approach associated with the practice of rural tourism in a "sun and water" landscape supported by a familial economic base. The presented results combine the surveys conducted during the fieldwork, application of questionnaires, informal interviews, photographic survey and bibliographic research. The study universe was composed by 50 tourists who stayed at referred the hotel establishment, between May and September 2015. The field research involved weekends and holidays, in order to identify some characteristics of tourists and visitors. Combined methods were required, highlighting the "analytical" and "quantitative" ones, as there is a close relationship between them. It was highlighted that the largest groups of visitors are from Rio Verde (25\%) and Quirinópolis (25\%), demonstrating that tourists who arrive at the destination are from places located in a 150kilometer radius. The tourist stay time in the rural enterprise is in a maximum of three days; hence, the researched landscape needs more investments.

KEYWORDS: Gouvelândia; Rural Tourism; Family Economy; Rural Contents.

\section{Introdução}

O lago da hidrelétrica de São Simão surge, em 1978, na paisagem regional drenada pelo rio Paranaíba, entre os estados de Minas Gerais e Goiás. Esse projeto foi responsável por acabar com antigos e rústicos territórios de lazer, mas provocou o surgimento de novas lógicas de lazer e turismo, ofertando novos produtos e serviços num território que é um mosaico de encontros e reencontros entre as culturas mineira e goiana no cerrado brasileiro.

Tal reservatório, constituído na década de 1970, possui $700 \mathrm{~km}^{2}$ de plano de água e potencializa a construção de residências de lazer, do turismo de pesca e do turismo rural. Essa paisagem do rio Paranaíba, apesar das marcas do agronegócio que a caracterizam, se tornou, principalmente a partir da década de 1990, um destino turístico regional de "sol e água", colocando a atividade turística como uma alternativa econômica de base local, em que foram aproveitadas as potencialidades do espelho de água, da culinária, da musicalidade sertaneja e dos remanescentes do bioma cerrado. Essa nova lógica regional abre perspectivas no que tange à expansão e diversificação para a economia assentada na valorização do trabalho familiar.

De fato, a região do lago de São Simão assinala um forte crescimento das atividades de lazer e turismo nos anos recentes, especialmente em Ipiaçu e Santa Vitória, em Minas Gerais; e em São Simão, Paranaiguara, Quirinópolis, Gouvelândia e Inaciolândia, em Goiás. São pequenas cidades 
que mantêm fortes traços de identidade com o espaço rural, um patrimônio que, se bem valorizado pelas políticas públicas locais, pode se tornar relevante no fortalecimento e desenvolvimento da atividade turística.

Nesse contexto, o estudo aqui proposto investiga uma pousada rural às margens do rio dos Bois, afluente do rio Paranaíba, no estado de Goiás. Como uma empresa familiar com infraestrutura, equipamentos, serviços de animação e lazer, ela tem potencializado o desenvolvimento do turismo rural no município de Gouvelândia, Goiás. Os diferentes usos da água do lago de São Simão têm ocasionado, ao longo das primeiras décadas do século XXI, alterações significativas, em virtude das variadas potencialidades, bem como da conotação econômica e social à qual tem se exposto.

Este artigo tem como objetivo apresentar e analisar o perfil dos visitantes que chegam à Pousada Rio dos Bois, ao veicular essa abordagem associada à prática do turismo rural numa paisagem de "sol e água" sustentada por uma base econômica familiar. O meio de hospedagem rural pesquisado iniciou suas atividades no ano de 2001; logo, é um espaço turístico que proporciona uma nova experiência na economia do município de Gouvelândia.

Os resultados apresentados conjugam os levantamentos efetuados durante os trabalhos de campo, a aplicação de questionários, as entrevistas informais, o levantamento fotográfico e a pesquisa bibliográfica. Portanto, este estudo contou, "com o trabalho de campo que proporcionou uma compreensão melhor das dinâmicas espaciais da escala de análise" (SANTOS; SILVA, 2015, p. 940). O universo da pesquisa foi composto por 50 turistas que se hospedaram na Pousada Rio dos Bois, de maio a setembro de 2015.

A investigação de campo envolveu períodos de finais de semana e feriados, visando à identificação de algumas características dos turistas e visitantes (perfil, origem, formação profissional, entre outras). Pressupôs-se no planejamento dos trabalhos de campo que, nesses dias, o fluxo de visitantes seria maior em virtude do lazer encontrado às margens do lago de São Simão.

Convém salientar que o processo de aplicação dos questionários foi aleatório, restringindo-se aos sujeitos com idade igual ou superior a 18 anos. Ao final desse trabalho, considerou-se que os resultados foram satisfatórios, diante do universo abrangido. Pode-se dizer que o referido artigo se utilizou de métodos mistos, destacando o "analítico" e o "quantitativo", haja vista que existe uma relação próxima entre eles.

A escassez de estudos sobre o turismo rural no município de Gouvelândia - em conjunto com a importância do lago da hidrelétrica de São Simão, sob a ótica ambiental e histórica -, bem como o fluxo constante de sujeitos que buscam áreas de lazer públicas e privadas foram fatores relevantes para a escolha do destino Pousada Rio dos Bois como objeto de pesquisa. Inicialmente, o trabalho partirá da discussão conceitual da categoria turismo rural.

\section{O turismo rural: discussão conceitual}


Pode-se destacar que o município de Gouvelândia é valorizado por sua dinâmica econômica ligada ao agronegócio. Entretanto, os sujeitos são valorizados por outros sentidos, diversidades e particularidades que se fazem presentes em diferentes paisagens do município que, no caso deste artigo, apresentam a lógica de turismo rural desenvolvido às margens do rio dos Bois.

Diante disso, é possível discorrer que o turismo no espaço rural é um fenômeno social complexo, diversificado e "[...] uma atividade que tem uma relação dialética com a sociedade [...] do ponto de vista financeiro e dependendo da estrutura social do país em questão" (BARRETTO, 1995, p. 71). Se bem planejado, esse segmento pode ser uma atividade econômica de base local geradora de riqueza, valorizando elementos culturais, naturais e históricos de pequenas cidades como Gouvelândia.

O debate sobre o turismo no espaço rural às margens do lago de São Simão propõe pensar o vivido "[...] como resultado de fatos que elevam o lugar como pertencimento, como uso do real' (SANTOS, 1999, p. 111). Considera-se, assim, o lugar como a "[...]a expressão de relações em que emerge o vivido, porque é nele que ocorre a unidade da vida social, seguramente, estaremos em condição de não banalizarmos as diferenças" (ibidem, p. 121).

Com base nessa contribuição, salienta-se que os conteúdos de ruralidades do interior de Goiás não são neutros, sem donos, e sim repletos de particularidades, em que os conteúdos subjetivos revelam arranjos e (re)organizações socioespaciais. Ou seja, eles expressam representações sociais e trajetórias culturais importantes que compõem os modos de vida de comunidades rurais que, por sua vez, usam os espaços sob outras lógicas não estabelecidas pela economia do agronegócio, somente, no tocante às grandes empresas agropecuárias que geram empregos e provocam problemas relacionados a questões ambientais, sociais e culturais.

Especificamente em relação à sua gênese, o turismo rural começou a se desenvolver no Brasil na década de 1980, em Lajes, no estado de Santa Catarina, mais precisamente na Fazenda Pedras Brancas, em 1985. Fiosi $(1999$, p. 5) narra esse acontecimento com as seguintes palavras:

Até então a cidade era conhecida pelos turistas como ponto de passagem para o que apenas pernoitaram por lá. Até que em 1984 foi criada a SERRATUR Empreendimentos e Promoções Turísticas, com o objetivo de fomentar as transformações de fazendas em hotéis. $O$ apelo era dormir numa casa de fazenda, acordar cedo e participar da ordenha, acompanhar o plantio ou a colheita e contar o gado. Tudo ao lado de funcionários que efetivamente trabalham no campo. Durante as refeições a chance de apreciar a culinária típica local, com ingredientes produzidos na própria fazenda como, paçoca de pinhão, rosquinha de coalhada, queijos, doces de leite e mel. 
$\mathrm{Na}$ produção teórica do conhecimento que aborda o turismo rural, Tiradentes (2012), Almeida e Blós (2000), Graziano da Silva et al. (2000), Santos (2013) e Rodrigues (2000) empregam a expressão Turismo em Espaço Rural (TER) para a totalidade dos movimentos turísticos nesse espaço. Tais autores distinguem o TER à medida que o conjunto da população usufrui dos rendimentos da atividade, ou seja, os empreendedores não precisam ser pessoas que vivam, exclusivamente, do (e no) campo.

Conceitualmente, o TER é qualquer tipo de atividade turística inserida, de maneira geográfica, nos espaços rurais, sem necessariamente se envolver com a dinâmica da propriedade rural e de seu cotidiano produtivo, podendo apresentar, em alguns casos, formatos tipicamente urbanos (ROQUE, 2001). Por outro lado, Pirete (2001, p. 21) compreende que a produção de turismo no meio rural corresponde ao exercício de "[...] atividades turísticas desenvolvidas em áreas rurais, resultando na produção de bens e serviços turísticos destinados a uma clientela atraída pelo consumo de bens do ambiente rural".

Sendo assim, até que ponto o rural indica um espaço de visitação? Vários questionamentos são elencados, em se tratando do desenvolvimento de base local relacionado ao turismo rural, mesmo sendo alternativo nesses lugares existem conteúdos culturais que têm sido desenvolvidos há décadas (TIRADENTES, 2012). Existe ali um espaço vivido, um cotidiano, e a intensificação do turismo criará novas lógicas de articulação econômica, aumentando a demanda por produtos locais e se traduzindo em novos arranjos produtivos.

De acordo com Tiradentes (2012), o turismo no espaço rural, visto como um turismo alternativo ao de massa, apesar de certas cautelas, pode ser uma forma interessante de desenvolvimento local, já que apresenta uma pluriatividade. Para isso, é necessário: utilizar recursos endógenos; ser centrado nas necessidades próprias da comunidade; capacitar atores sensibilizados, a exemplo dos produtores rurais; manter estratégias de desenvolvimento; constituir parcerias com o setor público; e implantar infraestrutura, considerando sobremaneira a preservação dos bens patrimoniais.

Nesse contexto, a posição de Silva Júnior (2004, p. 71) indica que, para incluir o turismo no espaço rural, este precisa ser agregado a serviços de boa qualidade que viabilizem seu consumo. Não há atração turística de uma simples cachoeira, reservatório hidrelétrico ou fazenda, se não houver determinados serviços para que o turista tenha acesso a ela. Vale ressaltar que, para alcançar essa dimensão, não basta pensar no turismo de base local e em suas perspectivas futuras. Acredita-se que o planejamento e 0 desenvolvimento de estratégias são fundamentais, além da reflexão acerca dos efeitos negativos que poderão surgir.

Nos apontamentos de Portuguez (1999), o turismo no espaço rural é a apropriação de uma dimensão do espaço geográfico. Quando isso ocorre, o turismo impõe sua lógica de uso, implicando o desenvolvimento de novas atividades, algumas com base agrícola e que vêm como uma forma de 
estimular geração de renda, em que os visitantes entrariam no processo produtivo por algum tempo.

À luz desse debate, cumpre ressalvar que as possibilidades de desenvolvimento do turismo, em qualquer comunidade rural:

[...] dependem dos laços que ela mantém com os centros urbanos, particularmente com as cidades de sua própria região. Apesar de predominarem as ruralidades nos indivíduos que vivem e trabalham no rural, elas vão modificando-se a partir da sua relação com as técnicas e com o urbano (CANDIOTTO, 2010, p. 117).

Desse modo, a análise sobre a atividade turística no espaço rural nos permite compreender as práticas socioculturais que indicam a capacidade de pequenos proprietários se relacionarem com o novo, isto é, as atividades não agrícolas. Nota-se, porquanto, que ajustes chegam aos lugares e especificam novas relações e fazeres. De acordo com Cruz (2003), o turismo em espaço rural nada mais é que a apropriação, pelo turismo, de outra dimensão do espaço geográfico.

Ao se apropriar de espaços rurais, o turismo impõe sua lógica de uso, no que tange aos conflitos que podem surgir a partir desse processo e, em geral, a prática turística promove a reorganização de tais espaços para que ela possa acontecer. O turismo em espaços rurais pode abarcar a visitação a propriedades rurais, com ou sem pernoite, e o envolvimento ou não do turista às práticas rurais comumente presentes nos espaços. Em função do uso turístico, os fatos apontados por Cruz (2003) ocorrem na paisagem do lago de São Simão.

Nesse entremeio, pode-se afirmar que o turismo rural é um fenômeno civilizacional suportado pela cultura, pela história, pelos povos e pela língua. Ele deve ser visto "[...] no âmbito de um paradigma moderno de gestão e planejamento de pessoas, do patrimônio, da cultura" (COSTA et al., 2014, p. 13). O objetivo desta discussão é veicular uma nova abordagem em que a atividade turística se afirma na paisagem do lago de São Simão, região que possui uma identidade associada aos encontros e reencontros das culturas goianas e mineiras, espalhadas pelos cerrados da bacia do rio Paranaíba.

Nesse território, usa-se a expressão "turismo rústico" para definir o turismo no espaço rural:

[...] uma vez entendido como aquele em que o turista possa comprar como produto a visitação/observação da paisagem rural e das atividades tradicionais, como festas religiosas, festas populares, folia de Reis, dança da catira, produção de leite e produtos derivados, dentre outras. O turista pode também contemplar a paisagem rural e se hospedar na comunidade, caso esta ofereça uma pousada, observar a ordenha manual, tomar leite no curral, cavalgar ou passear 
de carro de boi ou carroça, fazer trilhas dentre outras possibilidades (SOUZA; SANTOS, 2014, p. 486).

Para esses lugares, o turismo rural representa uma alternativa socioeconômica no âmbito da cidadania, de geração de emprego e fonte de renda, do desenvolvimento de base local, da promoção do desenvolvimento econômico e cultural, da conservação de recursos naturais, históricos e patrimoniais. Isso contribui para a criação e o desenvolvimento de produtos turísticos diversificados, respondendo a diversos tipos de motivações e a mercados mais abrangentes (COSTA et al., 2014).

Nas palavras de Cavaco (1999, p. 15), o desenvolvimento rural assenta na valorização de "[...] novas atividades econômicas, jogando tanto com novos produtos como com novos serviços. No fundo, trata-se em muitos casos de uma simples diversificação em ramos não inteiramente novos, mas apenas com novas funções e valores". Em síntese, constata-se que o turismo rural existe e subsiste como parte dessa nova realidade de desenvolvimento.

Nessa perspectiva, várias mudanças têm ocorrido no espaço rural goiano. Algumas aconteceram em razão da busca de novas fontes de renda pela população, "[...] dado que a modernização da produção tem levado à adoção de atividades não agrícolas, uma alternativa para a complementação dos rendimentos agrícolas, a exemplo do turismo rural, do lazer e dos pequenos negócios" (MATA; SANTOS, 2015, p. 37).

A força do turismo rural na região do lago de São Simão, enquanto nova atividade, deve se assentar não só nos recursos "sol e água", mas em produtos turísticos relacionados ao ambiente, às tradições goianas e mineiras, aos patrimônios paisagístico e histórico. Esses elementos podem levar à criação de um destino diversificado, articulando as potencialidades do bioma cerrado e promovendo o encontro das culturas dos estados de Goiás e Minas Gerais.

\section{Pousada Rio dos Bois, no município de Gouvelândia (GO): o recorte de pesquisa}

Gouvelândia está localizada na microrregião de Quirinópolis, no estado de Goiás, entre as coordenadas geográficas $19^{\circ} 04^{\prime} 11^{\prime \prime}$ sul e $51^{\circ} 06$ '11" oeste. Possui área de $831 \mathrm{~km}^{2}$ e altitude média de 395 metros. 0 recorte de pesquisa deste artigo encontra-se na zona rural do município, às margens do rio dos Bois e no limite com o município goiano de Inaciolândia. Essa drenagem, afluente do rio Paranaíba, nasce em Americano do Brasil, Goiás. Segundo Flauzino et al. (2010, p. 78), a área drenada pelo rio Paranaíba:

[...] é a segunda maior bacia da região hidrográfica do rio Paraná com uma área de $222.767 \mathrm{~km}^{2}$. A nascente do Rio Paranaíba situa-se na mata da Corda, no município de rio Paranaíba/MG, e sua bacia de captação abrange parte dos estados de Goiás, Minas Gerais, Mato Grosso do Sul e Distrito Federal. 
A vegetação dominante na área de estudo é remanescente de cerrado, porém bastante alterada pelo agronegócio e por suas lógicas capitalistas. O cerrado, segundo maior bioma brasileiro, é um mosaico de formações vegetais que variam desde campos abertos até formações densas de florestas que podem atingir 30 metros de altura: " $A$ cobertura arbórea e a densidade de árvores podem variar bastante entre as fisionomias, mas se observa um gradiente de valores entre as áreas campestres e as áreas florestais" (AGUIAR; CAMARGO, 2004, p. 17).

$O$ acesso à paisagem de turismo rural é feito pela rodovia estadual GO-206, km 58. Nesse lugar, o rio apresenta águas calmas e uma extensão adequada, o que permite a existência de lógicas de turismo, residências de lazer, atividades pesqueiras e produção de piscicultura. A Pousada Rio dos Bois (Figuras 1 e 2) é uma empresa familiar, que iniciou suas atividades a partir da aquisição de um rancho de lazer no ano de 2001.

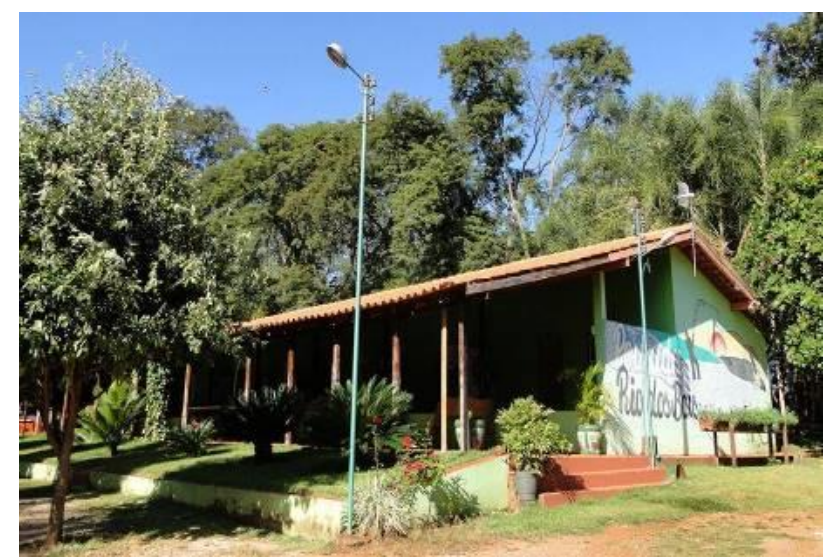

Figura 1: Pousada Rio dos Bois, à margem esquerda do Rio dos Bois, no município de Gouvelândia (GO).

Figure 1: Pousada Rio dos Bois, on the left bank of the Rio dos Bois, in the municipality of Gouvelândia (GO, Brazil).

Fonte: Elaboração dos autores.

Source: Elaboration of the authors.

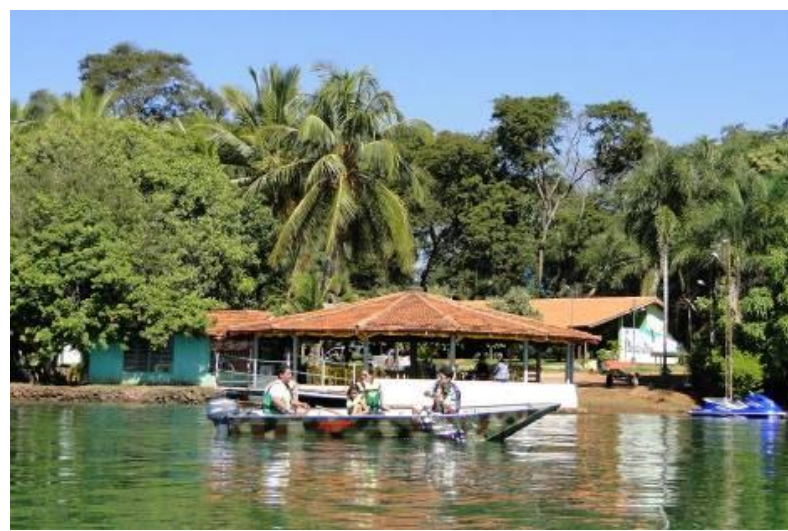

Figura 2: Quiosque e infraestrutura da Pousada as margens do Rio dos Bois.

Figure 2: Kiosk and infrastructure of the Pousada on the banks of the Rio dos Bois.

Fonte: Elaboração dos autores.

Source: Elaboration of the authors. 
Para gerir a pousada, não houve qualificação do capital humano, posto que os proprietários não tinham experiência no setor de prestação de serviços turísticos. A partir de 2011, após contatos com outras empresas e vendo a necessidade de uma evolução do nível profissional, foi abandonada a forma de gestão denominada pelo fundador como "arcaica", que não atendia às expectativas dos clientes.

$\mathrm{Na}$ segunda década do século XXI, houve inovações como uso da internet, incentivos ao lazer e turismo de pesca, expansão e qualificação dos serviços ofertados, com investimentos na infraestrutura da área envolvente. Desenvolveu-se um sistema de cozinha que reforça a tradição da culinária goiana e mineira, para atendimento dos hóspedes e visitantes que chegam ao lugar apenas para fazer suas refeições.

Os investimentos em infraestrutura e qualificação do capital humano visaram apresentar uma nova forma de gestão, para aumentar os lucros e recuperar os capitais investidos. Hoje, o trabalho desenvolvido está consolidado numa "cultura de atendimento familiar", pois a gestão e as prestações dos serviços são executadas, principalmente, pelo casal fundador, pelas filhas e pelos genros.

A pousada iniciou com nove apartamentos e dois banheiros externos; atualmente, está com 12 apartamentos com banheiros (suítes), arcondicionado, frigobar, TV e internet sem fio. No entanto, falta desenvolver um sistema de sinalização turística, de modo a garantir adequada visibilidade do empreendimento e maior alcance estratégico de desenvolvimento do turismo rural no município de Gouvelândia.

Durante os trabalhos de campo, foi possível perceber que os visitantes que chegam à pousada pretendem se reaproximar da natureza e das tradições da terra, mesmo por um curto espaço de tempo. Eles se interessam em vivências e experimentações relacionadas à natureza e ao modo de vida local, algo caracterizado por elementos singulares da cultura.

\section{Um olhar para os turistas: perfil social e econômico}

Conforme informado anteriormente, 0 universo da pesquisa foi composto por 50 turistas que se hospedaram na Pousada Rio dos Bois, de maio a setembro de 2015. Dentre os entrevistados, $40 \%$ são do sexo feminino e $60 \%$, masculino. Quanto ao tipo de grupo em que realizaram a visita, $83 \%$ respondentes indicaram que estavam com a família, em que vários casais estavam acompanhados dos filhos. Esse estudo do perfil da demanda turística busca definir quem, atualmente, é o visitante.

Com relação à residência do visitante, o Gráfico 1 mostra que os maiores grupos se referem às cidades de Rio Verde (25\%) e Quirinópolis (25\%); logo, os turistas que chegam ao destino são oriundos de lugares localizados num raio de 150 quilômetros. O deslocamento de seus domicílios até o empreendimento rural ocorreu predominantemente de carro. Os dados relativos aos municípios de origem dos entrevistados que vão aos finais de 
semana para o empreendimento rural em Gouvelândia (Gráfico 1) permitem compreender a relevância regional do destino.

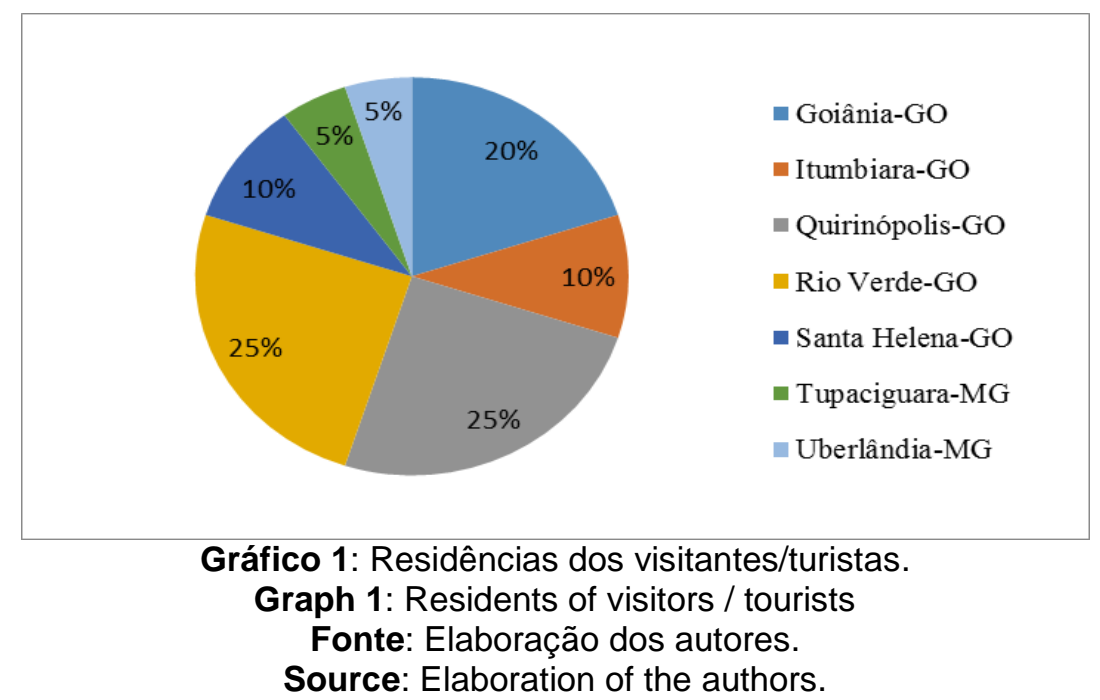

As profissões mais indicadas entre os respondentes estão presentes no Gráfico 2, e entre as mais citadas estão professores (15\%) e vendedores $(15 \%)$ - tais atividades ressaltam no atrativo rural um tipo de visitante eminentemente urbano. Com relação à forma como tomaram conhecimento da Pousada às margens do lago de São Simão, 100\% disseram que isso ocorreu por indicação de amigos.

A pesquisa demonstrou que a escolaridade dos informantes é alta (Gráfico 3): $30 \%$ concluíram o ensino superior e $15 \%$ têm superior incompleto. Espera-se que turistas com maior formação exijam dos gestores do empreendimento e do poder público local um desenvolvimento turístico qualificado e sustentado, garantindo a manutenção das condições ambientais, culturais e sociais dos territórios formadores do entorno do lago de São Simão.

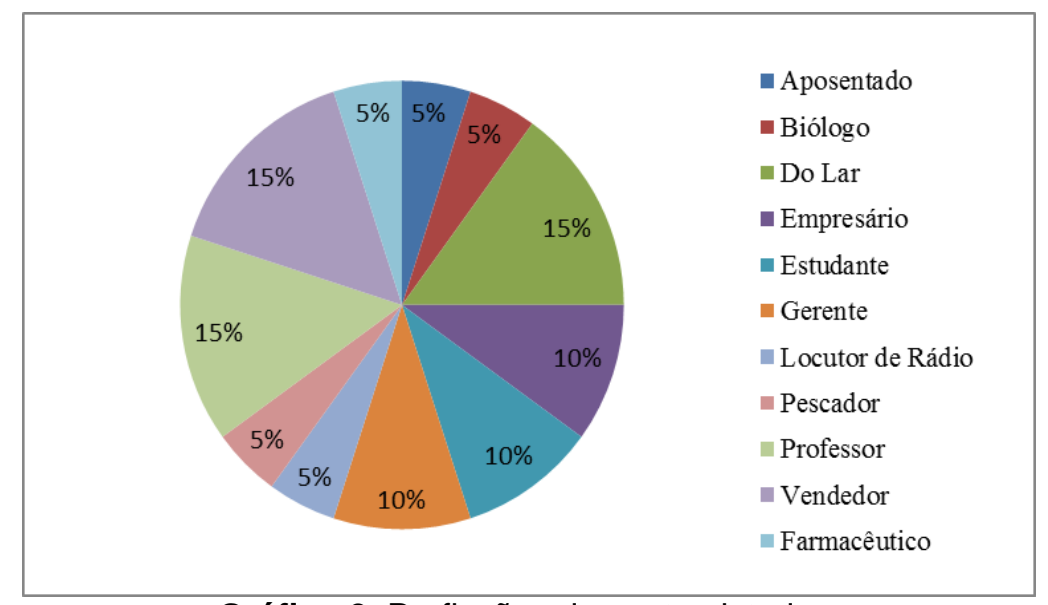

Gráfico 2: Profissões dos entrevistados.

Graph 2: Professions of the interviewees.

Fonte: Elaboração dos autores.

Source: Elaboration of the authors. 


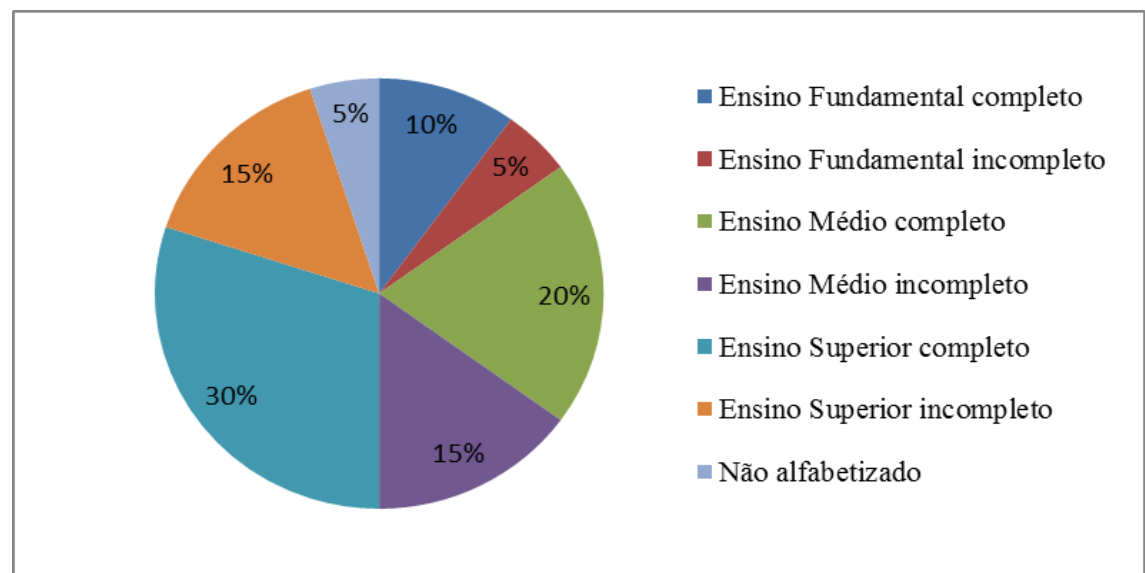

Gráfico 3: Escolaridade dos entrevistados.

Graph 3: Interviewee education.

Fonte: Elaboração dos autores.

Source: Elaboration of the authors.

De acordo com o Gráfico 4, o tempo de permanência dos turistas no empreendimento rural é de, no máximo, três dias, mostrando que a maioria (45\%) dos hóspedes permanece por esse período - $40 \%$ ficam no local por dois dias e $15 \%$, um dia. Dentre as constatações investigadas, tais períodos traduzem uma acentuada demanda pelos finais de semana.

Nesse entremeio, o grau de importância para determinar a escolha do destino turístico, atribuído pelos respondentes para diversos aspectos, é destacado no Gráfico 5. Observa-se que a tranquilidade do lugar é o fator mais observado, pois esse item contou com $46 \%$ das respostas. Informalmente, durante os trabalhos de campo, os turistas ponderaram que a paisagem proporciona um contato com o rio e a vegetação de cerrado e que $o$ atendimento familiar é diferenciado. Para $14 \%$, as refeições fornecidas pelo empreendimento são uma oportunidade de contato com a cultura local.

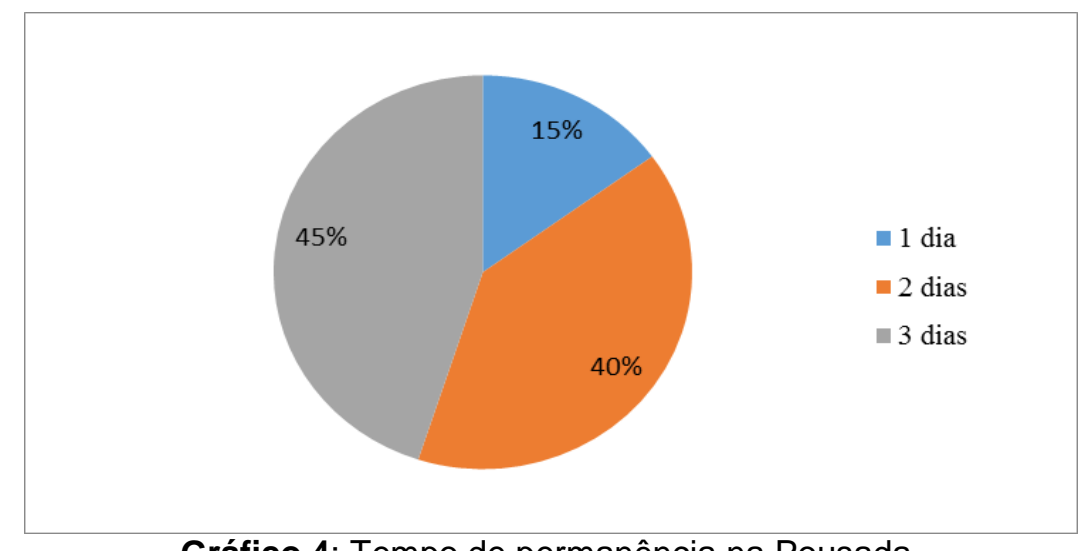

Gráfico 4: Tempo de permanência na Pousada.

Graph 4: Time spent at the Pousada.

Fonte: Elaboração dos autores.

Source: Elaboration of the authors. 


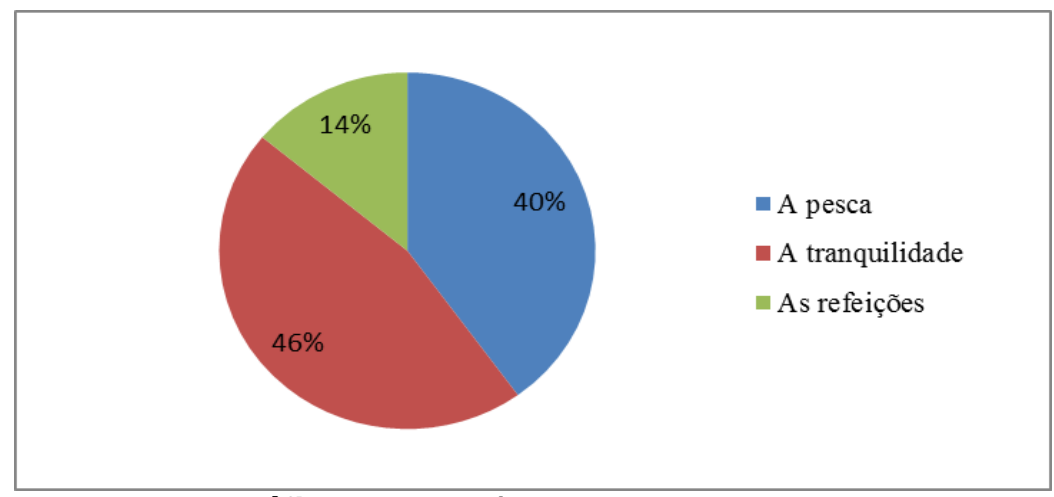

Gráfico 5: Importância atrativa do lugar.

Graph 5: Attractive place importance.

Fonte: Elaboração dos autores.

Source: Elaboration of the authors.

O Gráfico 6 apresenta que 38\% dos inquiridos procuram o lugar em função da qualidade do almoço ofertado. Conhecer as preferências e avaliações assinaladas pelos turistas pode se tornar um diferencial para o empreendimento, especialmente para gestores que têm uma visão estratégica de valorização do turismo rural associada ao lazer e à cultura dos povos do bioma cerrado.

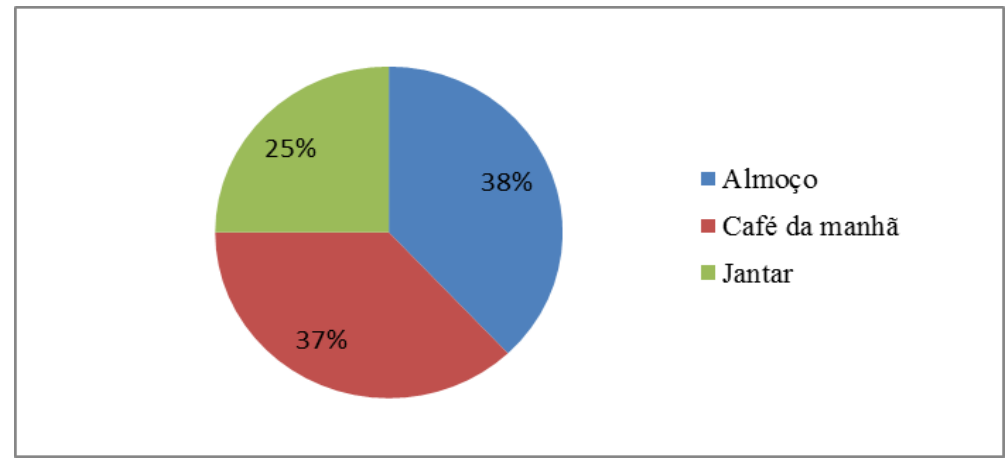

Gráfico 6: Preferência pelas refeições.

Graph 6: Preference for meals.

Fonte: Elaboração dos autores.

Source: Elaboration of the authors.

Enquanto isso, o Gráfico 7 possibilita conhecer os equipamentos e serviços mais utilizados pelos visitantes que chegam ao empreendimento às margens do lago de São Simão. Desses sujeitos, 40\% destacaram a importância de o lugar oferecer a internet sem fio. Os resultados mostram que a família gestora busca ofertar serviços modernos e diversificados, garantindo condições competitivas em relação a outros destinos de turismo rural existentes na região.

A partir do Gráfico 8, verifica-se que o turismo rural na paisagem pesquisada precisa de mais investimentos em divulgação, fato destacado por $41 \%$ dos inquiridos. Apenas $7 \%$ dos turistas responderam que o trabalho de mídia não precisa ser melhorado, pois está condizente com as expectativas deles. 
Nesse contexto, a divulgação poderá garantir condições competitivas diante de outros destinos turísticos com relativa similitude, pois tal investimento é fundamental para o processo de desenvolvimento do turismo rural no município de Gouvelândia e nas demais localidades no entorno do reservatório do lago de São Simão, nos estados de Goiás e Minas Gerais.

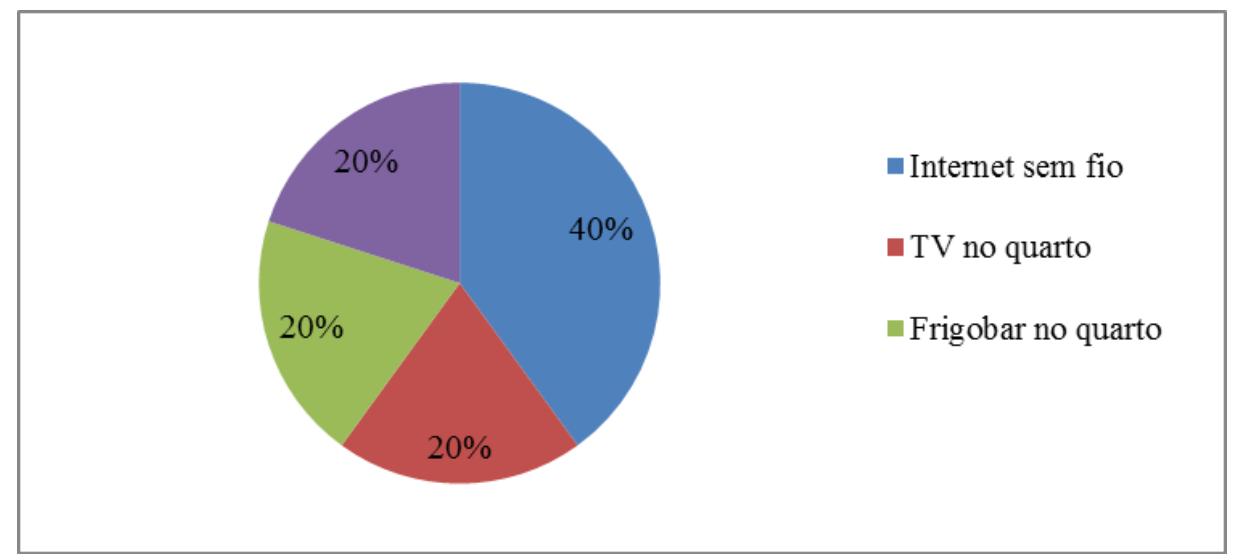

Gráfico 7: Tipos de equipamentos e serviços utilizados pelos visitantes.

Figure 7: Types of equipment and services used by visitors.

Fonte: Elaboração dos autores.

Source: Elaboration of the authors.

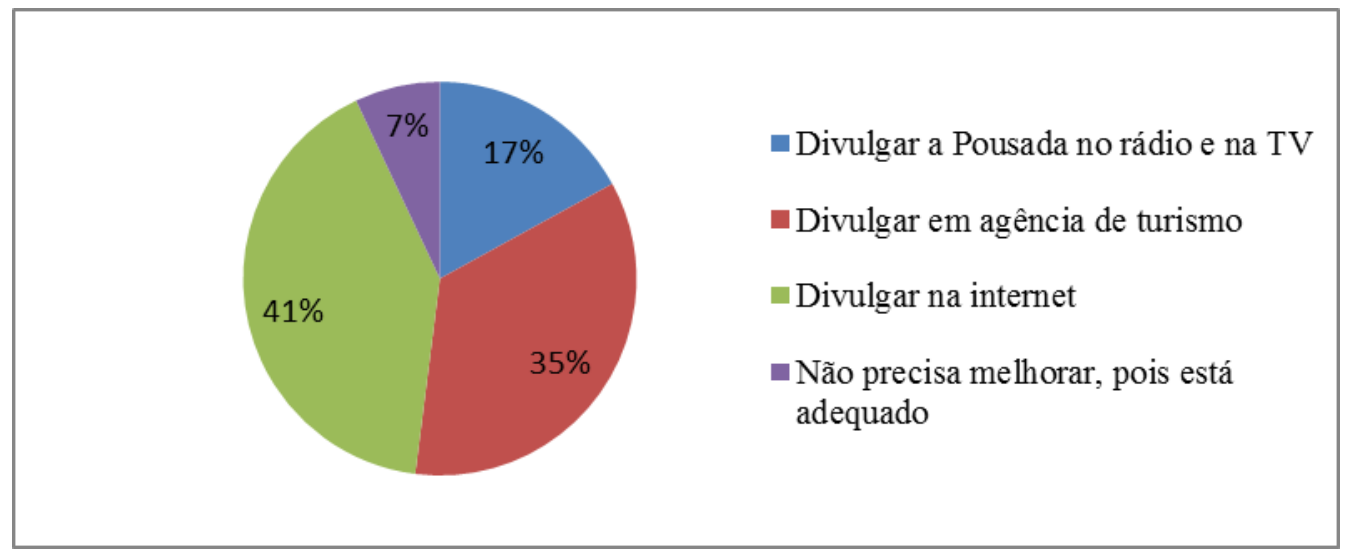

Gráfico 8: Divulgação do empreendimento rural de Gouvelândia.

Graph 8: Disclosure of rural development in Gouvelândia.

Fonte: Elaboração dos autores.

Source: Elaboration of the authors.

Para $100 \%$ dos entrevistados, falta apoio do poder público de Gouvelândia para as atividades ligadas ao turismo e lazer no município. É importante ressaltar que, na Prefeitura, não existe um setor ou uma pessoa pública responsável por desenvolver e apoiar essas atividades, assim como não há parcerias com a Goiás Turismo (órgão estadual) e o Ministério do Turismo (órgão nacional). Essa realidade tem dificultado a afirmação do turismo rural como uma alternativa de fonte de renda regional e de base local. 


\section{Algumas considerações}

Diante dos resultados apresentados, nota-se que o empreendimento de turismo rural às margens do lago da hidrelétrica de São Simão, no município de Gouvelândia, Goiás, é um destino de âmbito predominantemente regional e local, reforçado pela localização privilegiada e pelo acesso da rodovia estadual GO-206. Os turistas chegam de cidades importantes do cerrado brasileiro ao lugar, como Rio Verde (GO), Quirinópolis (GO), Goiânia (GO) e Uberlândia (MG).

A predominância de entrevistados de cidades regionais também pode ser explicada pelo viés da divulgação do destino, já que a maioria dos inquiridos soube do atrativo rural por indicação de amigos ou parentes, em contraste com a atividade desenvolvida em outras cidades de Goiás, como Caldas Novas, cidade de Goiás, Rio Quente e Pirenópolis, que detêm maior alcance estratégico por estarem articuladas com grandes empresas (agências e operadoras de turismo) nacionais que aumentam o poder de visibilidade desses destinos.

Vale lembrar que a maioria dos entrevistados chegou de carro à paisagem pesquisada aos finais de semana, isoladamente ou em grupos familiares. Não foram identificados grupos em excursões organizadas por agências ou empresas de turismo, uma vez que não existe um trabalho dos gestores para desenvolver e consolidar uma cultura de acolhimento para grupos que chegam de ônibus. A ação dos empresários do lugar está totalmente voltada para o visitante que se desloca no próprio automóvel.

Entre o serviço mais utilizado pelos visitantes está o de alimentação. Esse dado demonstra que há uma preferência pela culinária do lugar, seja por escala de importância cultural ou por outros motivos, como o fato de 0 restaurante estar aberto não somente aos hóspedes, como também àqueles que desejam apenas fazer uma das refeições do dia, especialmente moradores de cidades próximas, como Gouvelândia e Inaciolândia.

É fundamental sublinhar que os investimentos continuam na qualificação do capital humano, na infraestrutura e nos demais cenários de lazer do empreendimento rural. Outro fato observado diz respeito ao cuidado em preservar a fauna e flora local, não destruída pelo desenvolvimento do agronegócio regional: os gestores assumem que o território do lago de São Simão dispõe de potenciais de desenvolvimento turístico que subsidiam perspectivas relacionadas à expansão e diversificação do lazer e das demais atividades associadas a esse setor econômico.

Destarte, é possível discutir que o desenvolvimento do turismo rural, do lazer e de outras atividades turísticas na região investigada é uma nova atividade econômica sustentada pelo trabalho familiar, sendo que os gestores têm assumido a responsabilidade de expandir e diversificar essas iniciativas numa região onde o agronegócio é ator principal. Tais sujeitos são responsáveis por afirmar o novo e alternativo negócio, aproveitando as potencialidades do espelho de água, do cerrado e de uma população com 
forte identidade sustentada por um conjunto de raízes dos estados de Goiás e Minas Gerais.

\section{Referências bibliográficas}

AGUIAR, L.M.S.; CAMARGO, A.J.A.. Cerrado: ecologia e caracterização. Brasília: Embrapa, 2004.

ALMEIDA, J.A.A.; BLÓS, W. O marketing do turismo rural e o desenvolvimento sustentável. In: ALMEIDA, J.A.A.; FROEHLICH, M.; RIEDL, M. (Orgs.) Turismo rural e desenvolvimento sustentável. Campinas: Papirus, 2000.

BARRETTO, M. Manual de iniciação ao estudo do Turismo. Campinas: Papirus, 1995.

CANDIOTTO, L.Z.P. Circuito italiano de turismo rural (Colombo-PR). Cascavel: Edunioeste, 2010.

CAVACO, C. (Org.). Desenvolvimento rural: desafio e utopia. Lisboa: Centro de Estudos Geográficos, 1999.

COSTA, C.; BRANDÃO, F.; COSTA, R.; BREDA, Z. Turismo nos países lusófonos: conhecimento, estratégia e territórios. Lisboa: Escolar, 2014.

CRUZ, R.C.A. Introdução à Geografia do Turismo. 2. ed. São Paulo: Roca, 2003.

FIOSI, S. Turismo rural gera empregos e contém êxodo. Jornal Gazeta Mercantil, Caderno de Viagens e Negócios, São Paulo, 2 set. 1999, p. 5.

FLAUZINO, F.S.; SILVA, M.K.A.; NISHIYAMA, L.; ROSA, R. Geotecnologia aplicada à gestão dos recursos naturais da bacia hidrográfica do rio Paranaíba, no cerrado mineiro. Revista Sociedade \& Natureza, [s.l.], n. 22, abr. 2010.

GRAZIANO DA SILVA, J.; VILARINHO, C.; DALE, P.J. Turismo em áreas rurais: suas possibilidades e limitações no Brasil. In: ALMEIDA, J.A.A.; FROEHLICH, M.; RIEDL, M. (Orgs.) Turismo rural e desenvolvimento sustentável. Campinas: Papirus, 2000.

MATA, L.R.; SANTOS, J.C.V. O visitante na paisagem rural: lazer, festa e musicalidade sertaneja no município de Quirinópolis, Goiás. Turismo: Estudos \& Práticas, Mossoró, v. 4, n. 1, p. 28-55, jan./jun. 2015.

PIRETE, M.J. O novo rural e o turismo ofertado pelo Hotel-Fazenda Cachoeira Rio das Pedras: perspectivas e propostas para o turismo local. 2001. Dissertação (Mestrado em Geografia) - Instituto de Geografia da Universidade Federal de Uberlândia, Uberlândia, 2001.

PORTUGUEZ, A.P. Agroturismo e desenvolvimento regional. São Paulo: Hucitec, 1999.

RODRIGUES, A.B. (Org.) Turismo e geografia: reflexões teóricas e enfoques regionais. São Paulo: Hucitec, 2000.

ROQUE, A.M. Turismo no espaço rural: um estudo multicaso nas regiões sul e sudoeste de Minas Gerais. Lavras: UFLA, 2001. 
SANTOS, J.C.V. Região e destino turístico: sujeitos sensibilizados na geografia dos lugares. São Paulo: Allprint, 2013.

SANTOS, J.C.V.; SILVA, J.A. Olaria e Turismo Cultural: reflexões sobre o caso Alentejo-Portugal. Revista Turismo em Análise, São Paulo, v.26, n.4, p. 933-959, dezembro de 2015.

SANTOS, R.J. Pesquisa Empírica e Trabalho de Campo: algumas questões acerca do conhecimento geográfico. Revista Sociedade \& Natureza, n. 11, jan./dez. 1999.

SILVA JÚNIOR, J.H. A política interna no Brasil (1992-2002). Belo Horizonte: FACE-FUMEC C/Arte, 2004.

SOUZA, E.A.; SANTOS, J.C.V. Microrregião Pedra lisa: Tradições e potencialidades. In: URZEDO, M.F.A. Quirinópolis - cultura e desenvolvimento regional: mãos e olhares diferentes III (1832-2014). Goiânia: Kelps, 2014.

TIRADENTES, L. Turismo no espaço: realidade ou possibilidade? In: SIMPÓSIO DE GEOGRAFIA VALE DO PARANAÍBA - POR UMA GEOGRAFIA DO TURISMO DE BASE LOCAL: DESAFIOS E POSSIBILIDADES NO CERRADO, 9., 2012, Quirinópolis. Anais... Quirinópolis: UEG, 2012. 1 CD-ROM.

\section{Nota:}

1 Professor e Bolsista de Incentivo ao Pesquisador (BIP) da Pró-reitoria de Pesquisa e Pós-graduação da Universidade Estadual de Goiás (UEG).

Elinéia Lima Santana: Universidade Estadual de Goiás, Quirinópolis, GO, Brasil.

E-Mail: elineiageo@gmail.com

Link para o currículo Lattes:

Jean Carlos Vieira Santos: Universidade Estadual de Goiás, Quirinópolis, GO, Brasil.

E-Mail: svcjean@yahoo.com.br

Link para o currículo Lattes: http://lattes.cnpq.br/7542926208646393

Data de submissão: 06 de junho de 2016

Data de recebimento de correções: 21 de setembro de 2016

Data do aceite: 27 de novembro de 2016

Avaliado anonimamente 